\title{
An investigation on the ground motion parameters and seismic response of underground structures*
}

\author{
Hamid Reza Nejati ${ }^{1, \star}$ Morteza Ahmadi ${ }^{1}$ and Hamid Hashemolhosseini ${ }^{2}$ \\ ${ }^{1}$ Rock Mechanics Department, School of Engineering, Tarbiat Modares University, Tehran 14117-13116, Iran \\ 2 Mining Engineering Department, Isfahan University of Technology, Isfahan 84156-83111, Iran
}

\begin{abstract}
Peak ground acceleration (PGA), frequency content and time duration are three fundamental parameters of seismic loading. This study focuses on the seismic load frequency and its effect on the underground structures. Eight accelerograms regarding different occurred earthquakes that are scaled to an identical PGA and variation of ground motion parameters with ratio of peak ground velocity (PGV) to PGA, as a parameter related to the load frequency, are considered. Then, concrete lining response of a circular tunnel under various seismic conditions is evaluated analytically. In the next, seismic response of underground structure is assessed numerically using two different time histories. Finally, effects of incident load frequency and frequency ratio on the dynamic damping of geotechnical materials are discussed. Result of analyses show that specific energy of seismic loading with identical PGA is related to the seismic load frequency. Furthermore, incident load frequency and natural frequency of a system have influence on the wave attenuation and dynamic damping of the system.
\end{abstract}

Key words: ground motion parameter; load frequency; PGA; dynamic analysis; wave attenuation CLC number: P315.9 Document code: A

\section{Introduction}

Geotechnical structures exposed to dynamic loading is now more of a concern for the designer than it used to be 20 or 30 years ago, because the application range of these structures has been more developed, including embankments, earth dams, retaining walls, slopes, tunnels, caverns and foundations. Dynamic response of geotechnical structures has traditionally been attended, for design purposes, in an 'equivalent static' approach. This was based on magnification of vertical applied load or specifying of equivalent horizontal load. It is obvious that this method involves an insufficient accuracy because of different characteristic of static and dynamic loads. Nowadays the availabile software being able to deal explicitly with dynamic analysis of realistic structures with many degrees of

\footnotetext{
* Received 26 January 2012; accepted in revised form 6 May 2012; published 10 June 2012.

^ Corresponding author. e-mail: nejatihmd@gmail.com

(C) The Seismological Society of China, Institute of Geophysics, China Earthquake Administration, and Springer-Verlag Berlin Heidelberg 2012
}

freedom makes this type of analysis be a part of design structures.

By definition, dynamic load is a type of load that changes in the direction or quantity of force during operation time. Based on the mentioned definition, almost all loads in nature are dynamic, because those are time dependent. In many cases, however, the variation of load magnitude occurs in a slow rate and it can be supposed as a static load. There is not a certain loading rate or frequency as a threshold to distinguish the static and dynamic loading, because a load varies slowly or is fast only in relation to the period time of structure (Kappos, 2002).

Effect of dynamic loading frequency on the response of geotechnical materials has been considered in some of studies. Jafari et al. (2004) studied the mechanical behavior of rock joints under cyclic loading and showed that continuous reduction of shear strength takes place with frequency increasing. Wang et al. (2007) considered the closure of rock joint under dynamic loading with different frequencies and indicated that normal displacement of joint with special asperity 
decreases with loading frequencies increasing. Numerous studies have been performed to investigate the effect of loading rate on the deformation mode of rock materials. Results have revealed that decreasing of the loading rate generally causes rock deformation mode to change from brittle to ductile deformation mode (Sano et al., 1981; Lajtai et al., 1991).

Frequency does not play an important role in assessing the shear strength of intact rocks, as shown by Burdine (1963), Haimson and Kim (1972) and Ray et al. (1999). Further, Chen et al. (2005) considered the dynamic response and failure behavior of rocks subjected to dynamic loading with the frequency ranging from 0.5 to $5 \mathrm{~Hz}$ and found that the obtained strain rate increases with the increase of load frequency.

In this study, some fundamental considerations regarding the seismic load frequency and its effect on the wave attenuation, stress distribution and stability of underground structure were performed.

\section{Ground motion parameters}

Ground motion parameters are a number of effective classical parameters which are derived from seismic accelerograms. The parameters are key issues in characterizing earthquake damage in structures (Alvanitopoulos et al., 2010). In the recent years, many studies have been performed to analyze the earthquake motion records. Douglas (2003) reviewed the attenuation equa- tion and showed that little agreement has been reached in the past 30 years of ground motion estimation relation studies. Strasser and Bommer (2009) evaluated a dataset of earthquake records with large value of PGA (peak ground acceleration) $>1 \mathrm{~g}$ or PGV (peak ground velocity) $>100 \mathrm{~cm} / \mathrm{s}$ and interoperated them. They tried to classify causative physical processes according to a uniform nomenclature. Alvanitopoulos et al. (2010) presented new crucial characteristic seismic parameters which provide information pertinent to the damage indicators of the structures. Baruah et al. (2011) investigated ground motion parameters for Shillong-Mikir plateau of northeastern India. They presented empirical relations for ground motions as a function of earthquake magnitude, fault type, source depth, and velocity characterization of medium and distance.

PGA is usually used to describe the intensity of ground motion in conventional seismic hazard analyses (Kavazanjian et al., 1985). However, PGA that is calculated by attenuation relations is not enough criteria for determination of "design base earthquake" time history because, in addition to PGA, seismic loads frequency and duration of strong ground motion affect the earthquake intensity.

Table 1 presents ground motion parameters of eight occurred earthquakes (Seismosoft, 2011; PEER Database, 2005). In all of the time histories, PGAs are scaled to $0.5 \mathrm{~g}$ to evaluate the effect of load frequency and time duration on the ground motion parameters.

Table 1 Scaled ground motion parameters of different earthquakes

\begin{tabular}{ccccccccccccc}
\hline $\begin{array}{c}\text { Earth- } \\
\text { quake }\end{array}$ & $\begin{array}{c}\text { Original } \\
\text { PGA } / \mathrm{g}\end{array}$ & $\begin{array}{c}\text { Scaled } \\
\text { PGA } / \mathrm{g}\end{array}$ & $\begin{array}{c}\mathrm{PGV} \\
/\left(\mathrm{cm} \cdot \mathrm{s}^{-1}\right)\end{array}$ & $\begin{array}{c}\mathrm{PGD} \\
/ \mathrm{cm}\end{array}$ & $\begin{array}{c}\mathrm{PGV} \\
\mathrm{PGA}\end{array}$ & $\begin{array}{c}a_{\mathrm{rms}} \\
/\left(\mathrm{cm} \cdot \mathrm{s}^{-2}\right)\end{array}$ & $\begin{array}{c}T_{\mathrm{d}} \\
/ \mathrm{s}\end{array}$ & $\begin{array}{c}I_{\mathrm{a}} \\
/\left(\mathrm{m} \cdot \mathrm{s}^{-1}\right)\end{array}$ & $\begin{array}{c}\text { SED } \\
/\left(\mathrm{cm}^{2} \cdot \mathrm{s}^{-1}\right)\end{array}$ & $\begin{array}{c}\text { ASI } \\
/(\mathrm{g} \cdot \mathrm{s})\end{array}$ & $\begin{array}{c}T_{\mathrm{p}} \\
/ \mathrm{s}\end{array}$ & $\begin{array}{c}a_{\mathrm{rms}} \times \\
/ T_{\mathrm{d}}\end{array}$ \\
\hline Chi-Chi $^{\mathrm{a}}$ & 0.78 & 0.5 & 73.752 & 87.574 & 0.15 & 57 & 40 & 1.997 & 13888.2 & 0.374 & 0.58 & 2280 \\
Chi-Chi $^{\mathrm{b}}$ & 0.69 & 0.5 & 82.57 & 75.561 & 0.168 & 61 & 40 & 2.298 & 15119.77 & 0.465 & 0.58 & 2440 \\
Corralitos & 0.69 & 0.5 & 20.342 & 3.451 & 0.041 & 92 & 8.45 & 1.106 & 244.675 & 0.397 & 0.28 & 777 \\
Emeryville & 0.25 & 0.5 & 75.066 & 20.443 & 0.153 & 105 & 20.53 & 3.468 & 8231.086 & 0.356 & 0.68 & 2155 \\
Friulli & 0.47 & 0.5 & 35.164 & 7.708 & 0.072 & 72 & 20 & 1.577 & 677.345 & 0.432 & 0.26 & 1440 \\
Hollister & 0.13 & 0.5 & 32.165 & 4.362 & 0.066 & 85 & 15 & 1.679 & 510.193 & 0.547 & 0.4 & 1275 \\
Sakaria & 0.57 & 0.5 & 80.129 & 33.867 & 0.163 & 112 & 20 & 3.847 & 5614.157 & 0.495 & 0.28 & 2240 \\
Tabas & 0.90 & 0.5 & 13.823 & 2.59 & 0.028 & 96 & 6.56 & 0.94 & 99.91 & 0.142 & 0.04 & 629 \\
\hline
\end{tabular}

Note: a. Longitudinal component; b. Transversal component. PGA, PGV, PGD denote respectively peak ground acceleration, peak ground velocity and peak ground displacement. $a_{\mathrm{rms}}$ denotes root mean square of acceleration time history, $T_{\mathrm{d}}$ denotes time duration of strong motion, $I_{\mathrm{a}}$ means Arias intensity, SED means specific energy density, ASI denotes acceleration spectrum intensity, and $T_{\mathrm{p}}$ denotes predominant period.

As shown in Table 1, although the time histories are scaled to an identical PGA, the other ground motion parameters are different. This is because frequency contents and time durations of time histories are dif- ferent. Whereas ground motion velocity computed by integral of motion acceleration, the ratio of $\mathrm{PGV} / \mathrm{PGA}$, can be used as an index of earthquake frequency content. In other words, the ratio of $\mathrm{PGV} / \mathrm{PGA}$ is known 
as a function of load frequency, so that for a simple harmonic motion with frequency of $f$, the ratio will be $1 / 2 \pi f$.

Arias intensity $\left(I_{\mathrm{a}}\right)$, specific energy density (SED) and root mean square of acceleration time history $\left(a_{\mathrm{rms}}\right)$ are defined as

$$
\begin{aligned}
& I_{\mathrm{a}}=\frac{\pi}{2 \mathrm{~g}} \int_{0}^{T_{\mathrm{d}}} a^{2}(t) \mathrm{d} t, \\
& \mathrm{SED}=\int_{0}^{T_{\mathrm{d}}} v^{2}(t) \mathrm{d} t,
\end{aligned}
$$

and

$$
a_{\mathrm{rms}}=\sqrt{\frac{1}{T_{\mathrm{d}}} \int_{0}^{T_{\mathrm{d}}} a^{2}(t) \mathrm{d} t},
$$

where $a(t)$ represents the acceleration time history and $T_{\mathrm{d}}$ is time duration of strong motion in acceleration record (Kavazanjian et al., 1985; Arias, 1970).

Variation of $a_{\mathrm{rms}}$, Arias intensity and SED with the ratio of $\mathrm{PGV} / \mathrm{PGA}$ are depicted in Figures $1 \mathrm{a}-1 \mathrm{c}$.
Figure 1a shows that $a_{\text {rms }}$ has no significant relationship with the ratio of $\mathrm{PGV} / \mathrm{PGA}$, while Arias intensity and SED have a significant relationship with the ratio of $\mathrm{PGV} / \mathrm{PGA}$. This finding infers that Arias intensity and specific energy of time histories with identical PGA is related to the frequency content of the seismic load. Therefore, PGA has generally a strong limitation on the measurement of seismic intensity.

Figure 1c shows that increasing of $\mathrm{PGV} / \mathrm{PGA}$ increases the value of SED. The work-energy equation for one-dimensional motion confirms the result of Figure 1c, so that dynamic loads energy has an inverse relation with load frequency or has a direct relationship with the ratio of PGV/PGA (Ghazvinian et al., 2010). Whereas the time duration of considered time histories is different, there is no significant relationship between $a_{\text {rms }}$ and PGV/PGA, but the correlation between $a_{\mathrm{rms}} \times T_{\mathrm{d}}$ and the ratio of $\mathrm{PGV} / \mathrm{PGA}$ is reasonable (Figure $1 \mathrm{~d}$ ).
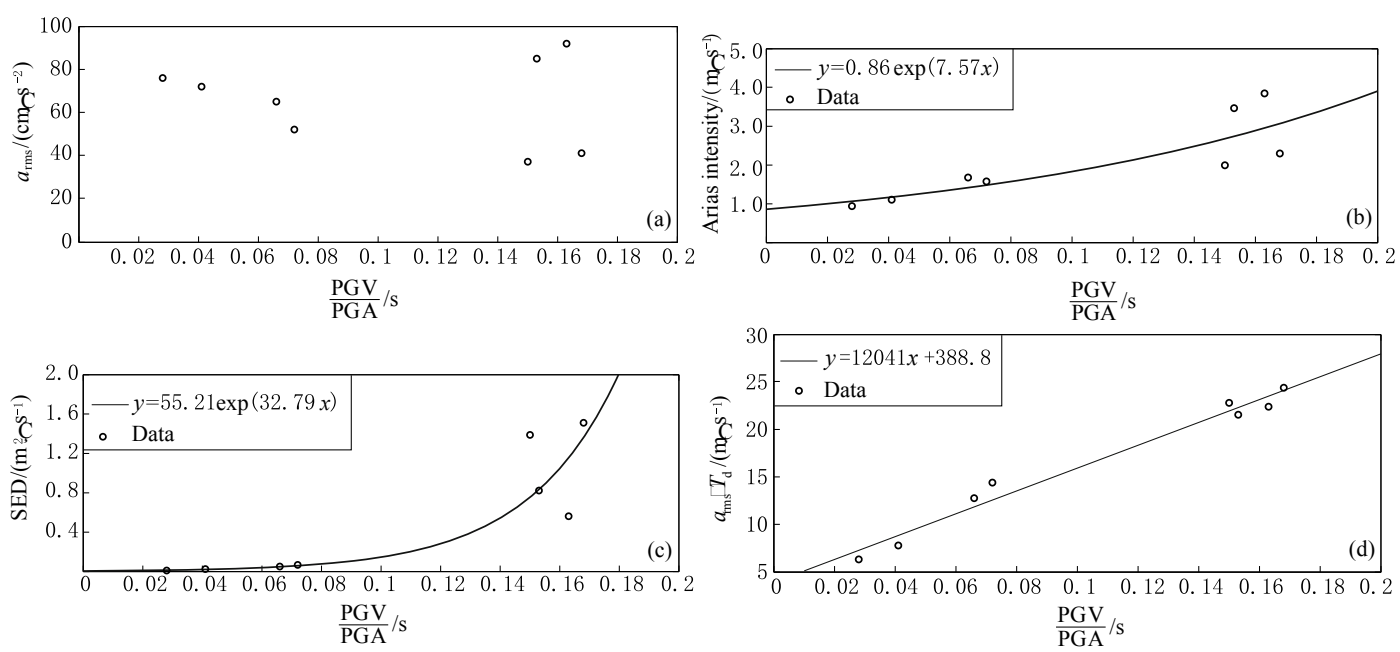

Figure 1 Variation of ground motion parameters ratio of PGV/PGA with RMS acceleration (a), Arias intensity (b), specific energy density (c), and $a_{\mathrm{rms}} \times T_{\mathrm{d}}(\mathrm{d})$.

\section{Seismic behavior of undergro- und structures}

As mentioned before, the ratio of $\mathrm{PGV} / \mathrm{PGA}$ represents the frequency content of seismic load. Power et al. (1996) proposed the value of PGV/PGA at surface in rock and soil based on the source to site distance and earthquake magnitude (Table 2).

As shown in Table 2, the value of $\mathrm{PGV} / \mathrm{PGA}$ increases with decreasing of the shear wave velocity in the site sediment. Furthermore, earthquake magnitude and distance to source has a direct relationship with the ratio of $\mathrm{PGV} / \mathrm{PGA}$.

\subsection{Lining deflection under seismic loading}

When seismic waves propagate in the direction perpendicular to tunnel axis, ovaling deformation may occurr (Wang, 1993). Ovaling deformation is one of the most significant influences on the tunnel lining, e.g., lining deflection, under seismic loading (Penzien, 2000). Figure 2 depicts a schematic view of ovaling deformation in a circular tunnel. Wang (1993), Penzien (2000) and Hashash et al. (2001) evaluated ovaling deformation of underground tunnel under seismic tunnel. Ratio 
of PGV/PGA has been utilized in the proposed method and its influence on the maximum free-field shear strain of rock or soil medium is considered (Hashash et al., 2001). In this section, importance of PGV/PGA on the seismic response of tunnel lining under seismic loading is investigated. For this purpose, assuming full-slip interface, lining deflection, $\Delta d_{\text {lining, }}$, of a circular tunnel under various seismic conditions (Table 2) is considered.

Table 2 Ratios of PGV/PGA at surface in rock and soil for various earthquake magnitude and source distance (Power et al., 1996)

\begin{tabular}{|c|c|c|c|c|}
\hline \multirow{2}{*}{ Sediment types } & \multirow{2}{*}{$M_{\mathrm{W}}$} & \multicolumn{3}{|c|}{$\mathrm{PGV} / \mathrm{PGA} /\left(\mathrm{cm} \cdot \mathrm{s}^{-1} \cdot \mathrm{g}^{-1}\right)$ for difference source to site distance $d$} \\
\hline & & $0<d<20$ & $20<d<50$ & $50<d<100$ \\
\hline Rock & 6.5 & 66 & 76 & 86 \\
\hline \multirow[t]{2}{*}{$v_{\mathrm{S}} \geq 750 \mathrm{~m} / \mathrm{s}$} & 7.5 & 97 & 109 & 97 \\
\hline & 8.5 & 127 & 140 & 152 \\
\hline Stiff soil & 6.5 & 94 & 102 & 109 \\
\hline \multirow[t]{2}{*}{$200<v_{\mathrm{S}}<750 \mathrm{~m} / \mathrm{s}$} & 7.5 & 140 & 127 & 155 \\
\hline & 8.5 & 180 & 188 & 193 \\
\hline Soft soil & 6.5 & 140 & 132 & 142 \\
\hline \multirow[t]{2}{*}{$v_{\mathrm{S}} \leq 200 \mathrm{~m} / \mathrm{s}$} & 7.5 & 208 & 165 & 201 \\
\hline & 8.5 & 269 & 244 & 251 \\
\hline
\end{tabular}
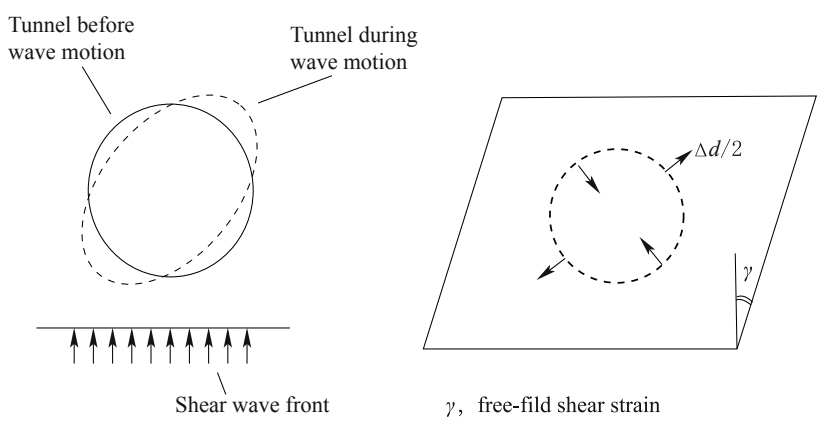

$\gamma$, free-fild shear strain

Figure 2 Schematic view of ovaling deformation in tunnel (Wang, 1993).

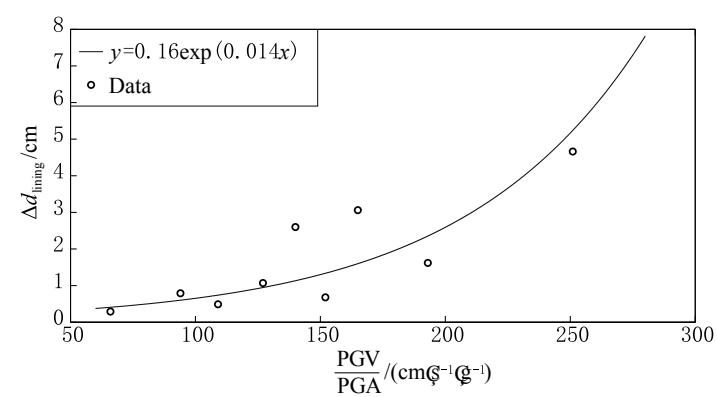

Figure 3 Variation of lining deflection with the ratio of $\mathrm{PGV} / \mathrm{PGA}$.

Figure 3 indicates the effect of $\mathrm{PGV} / \mathrm{PGA}$ ratio on the $\Delta d_{\text {lining. }}$. The result of this figure is related to a tunnel lining of concrete support with $30 \mathrm{~cm}$ thickness, $24 \mathrm{MPa}$ yield strength and $24 \mathrm{GPa}$ Young's modulus. The radius and depth of tunnel are assumed 4 and 20 meters, respectively.

Figure 3 shows that lining deflection increases with the value of PGV/PGA increasing. Lining deflection has an exponential relationship with the ratio of PGV/PGA. This finding can be confirmed by the result of previous analyses that are depicted in Figure 1c because the specific energy of seismic load has a direct relationship with $\mathrm{PGV} / \mathrm{PGA}$.

\subsection{Numerical modeling}

In this section, effect of seismic load frequency on the underground structures was considered numerically. For this purpose, a railway tunnel in the south of Iran, which is located at a depth of 20 meters, was considered as a case study. Geomechanical properties of the tunnel surrounding rock mass are included such as deformability coefficient of $1.3 \mathrm{GPa}$, a Poisson's ratio of 0.25 , a cohesion of $200 \mathrm{KPa}$, a friction angle of $25^{\circ}$, a tensile strength of $24 \mathrm{KPa}$ and a density of $2.7 \times 10^{3} \mathrm{~kg} / \mathrm{m}^{3}$. Two separate time histories with different specifications are used for dynamic analysis. The first one is related to Chi-Chi earthquake in Taiwan of China with local magnitude of $M_{\mathrm{L}} 7.3$ which is recorded in a soil media. The focal depth of this earthquake is $7.5 \mathrm{~km}$. Also the distance of earthquake record station from epicenter is $2.5 \mathrm{~km}$ (Wang et al., 2001). Figure 4a shows this time history with peak ground acceleration $0.78 \mathrm{~g}$. The second time history is related to Avaj earthquake in Iran with $M_{\mathrm{W}} 6.5$ that is recorded in the Avaj seismography station. Avaj station is located in the rock-bed and $28 \mathrm{~km}$ distance from the epicenter. Focal depth of this earthquake is $7 \mathrm{~km}$ (BHRC, 2008). Figure 4b shows this time history with peak ground acceleration $0.5 \mathrm{~g}$. Fourier 
amplitude spectra of both earthquakes which indicate frequency content of those time histories are also shown in Figures 5a and 5b.

The Fourier amplitude spectrum is computed by means of fast fourier transformation (FFT) of the input time history. The Fourier amplitude spectrum shows how the amplitude of the ground motion is distributed with respect to frequency (or period), effectively meaning that the frequency content of the given accelerogram can be fully determined (Clough and Penzien, 1994).
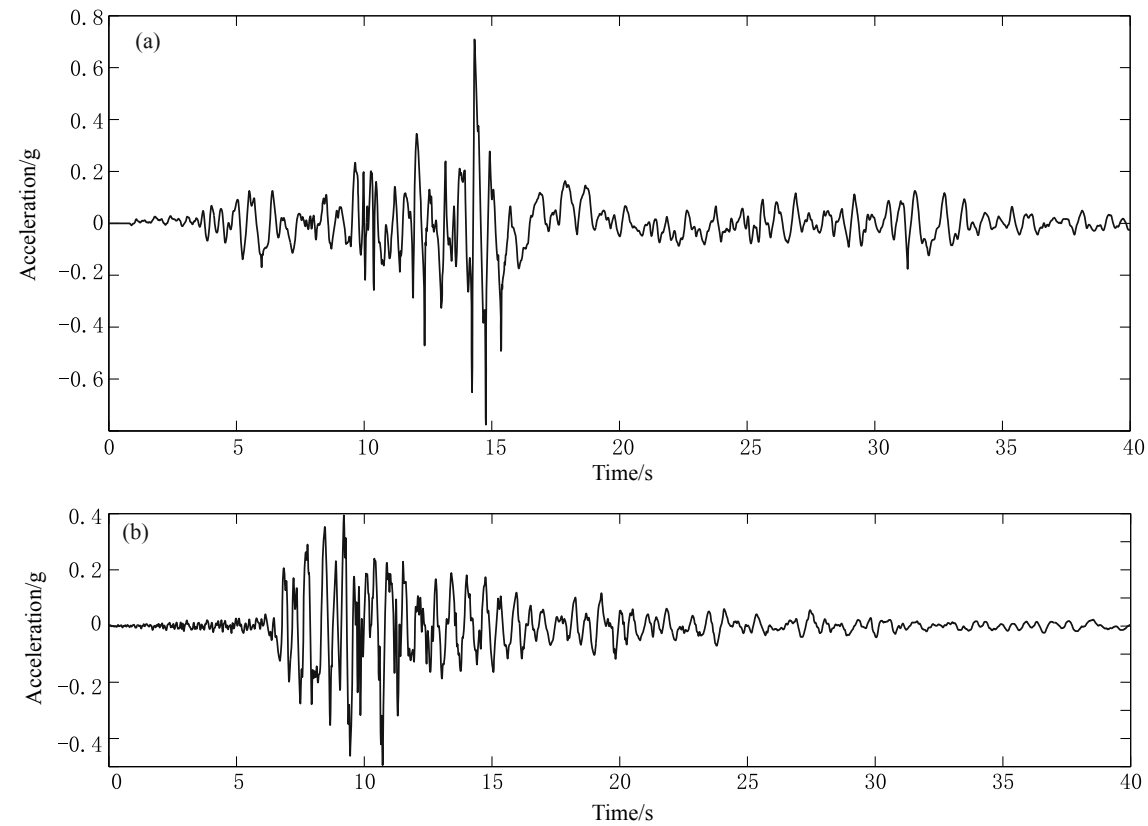

Figure 4 Time histories of the Chi-Chi (a) and Avaj (Nejati, 2009) earthquakes (b).
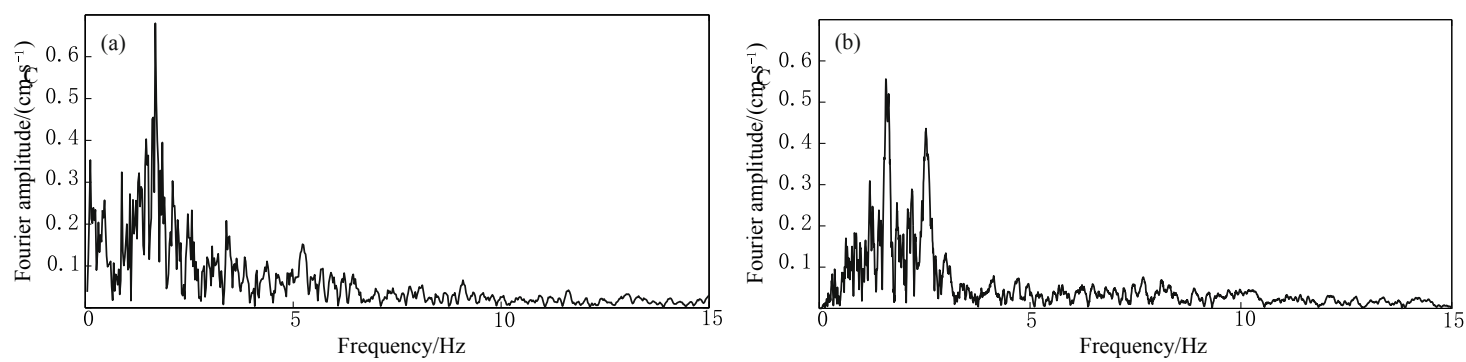

Figure 5 Fourier amplitude spectra of the Chi-Chi (a) and Avaj earthquakes (b).

As shown in Figure 5, frequency contents of the Chi-Chi and Avaj earthquakes are completely different from each other. Although both central frequencies are $1.6 \mathrm{~Hz}$, but the Fourier amplitude of low frequencies in both earthquakes are different.

Initially, both time histories are scaled for PGA equal to $0.35 \mathrm{~g}$ in order to examine differences in frequency contents of both loads. For this purpose the Chi-Chi time history is multiplied by a coefficient of 0.47 . This coefficient is ratio of 0.35 (target PGA) to the Chi-Chi accelerogram PGA (0.78). This scaled coefficient only changes the amplitude of ground motion and not the frequency. Similarly the Avaj time history is multiplied by 0.7 . Hereby the PGA of both time histories is scaled to $0.35 \mathrm{~g}$. Thus the only difference of these scaled time histories is their frequency contents. Table 3 presents ground motion amplitude parameters for both of the scaled Chi-Chi and Avaj time histories.

As shown in Table 3, in spite of scaling Chi-Chi and Avaj accelerograms to $0.35 \mathrm{~g}$, their peak velocities and displacements remain different. 
Table 3 Ground motion amplitude parameters for two scaled Chi-Chi and Avaj time histories

\begin{tabular}{|c|c|c|c|c|c|}
\hline \multirow{2}{*}{$\begin{array}{c}\text { Time } \\
\text { history }\end{array}$} & \multirow{2}{*}{$\begin{array}{c}\text { Scaled } \\
\text { coefficient }\end{array}$} & \multicolumn{3}{|c|}{ Scaled amplitude parameters } & \multirow{2}{*}{$\frac{\mathrm{PGV}}{\mathrm{PGA}} / \mathrm{s}$} \\
\hline & & $\mathrm{PGA} / \mathrm{g}$ & $\mathrm{PGV} /\left(\mathrm{cm} \cdot \mathrm{s}^{-1}\right)$ & $\mathrm{PGD} / \mathrm{cm}$ & \\
\hline Chi-Chi & 0.47 & 0.35 & 43 & 22 & 0.12 \\
\hline Avaj & 0.78 & 0.35 & 28 & 5.9 & 0.08 \\
\hline
\end{tabular}

Horizontal displacement of tunnel wall is determined after applying Avaj and Chi-Chi time histories to the numerical model to evaluate the responses and comparison of the effects of both earthquake loadings on the studied tunnel. These horizontal displacements are shown in Figures 6a and 6b, respectively.

It can be noticed from Figure 6 that the horizontal displacement occurring at the center of tunnel wall due to the applied Avaj seismic loading is $0.55 \mathrm{~cm}$, whereas for Chi-Chi seismic loading is more than $3 \mathrm{~cm}$. In other words, Avaj seismic load, with smaller value of $\mathrm{PGV} / \mathrm{PGA}$ ratio, causes less destructive effect on the structure than Chi-Chi seismic load.
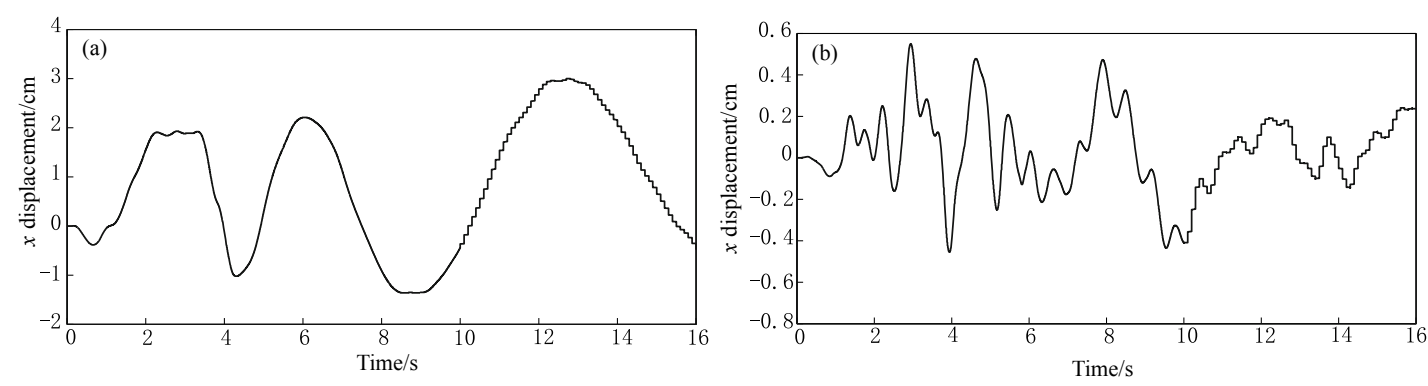

Figure 6 Horizontal displacement of tunnel wall with Chi-Chi (a) and Avaj records (b).

\section{Effect of load frequency on the wave attenuation}

Dynamic damping of geotechnical materials is one of the most effective factors controlling response of geomechanical structures under dynamic loading (Chang, 1989). Wave attenuation in geotechnical materials is a complex phenomenon that is due to energy loss as a result of internal friction. Whereas dynamic load frequency has influence on the stress distribution, then load frequency could be an effective factor on the wave attenuation. The numerical model depicted in Figure 7 was developed to investigate the effect of load frequency on the stress distribution and wave attenuation. Harmonic dynamic loading with constant amplitude and variable frequency were applied to the left side of this model to assess the peak particle velocities at points $A$ and $B$.

Dynamic loading applied to the numerical model is a harmonic (sinusoidal) stress wave with constant amplitude (1.0 MPa) and variable angular frequency (2$120 \mathrm{rad} / \mathrm{s})$. It should be mentioned that frequency content of seismic loads is different from harmonic loads, because seismic loads do not have a certain frequency and contain a frequency spectrum. However, the effect of load frequency on the wave attenuation can be better explained using simple harmonic loading. Figure 8a presents the variation of maximum particle velocity at points $A$ and $B$ versus angular frequency due to dynamic loading. It can be inferred from Figure 8a that any increase in frequency of the input dynamic loading causes decreasing of peak particle velocity. This fact shows that any increase in load frequency affects the stress distribution and wave energy. Hence, the larger the loading frequency, the lower the load energy will be.

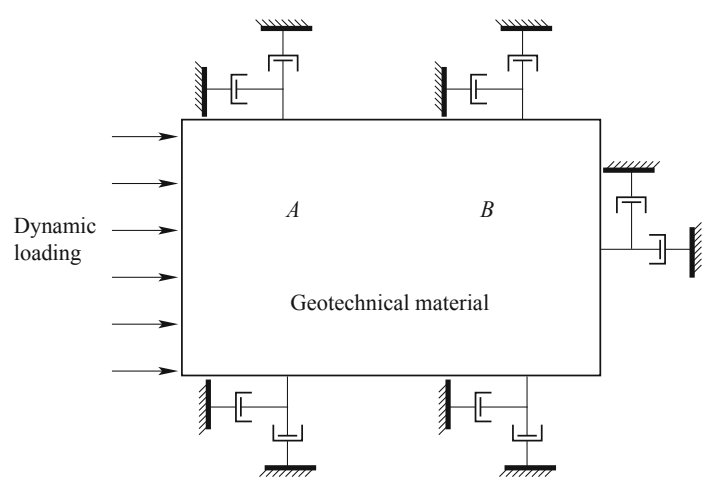

Figure 7 Numerical model of harmonic wave propagation through geotechnical material. 

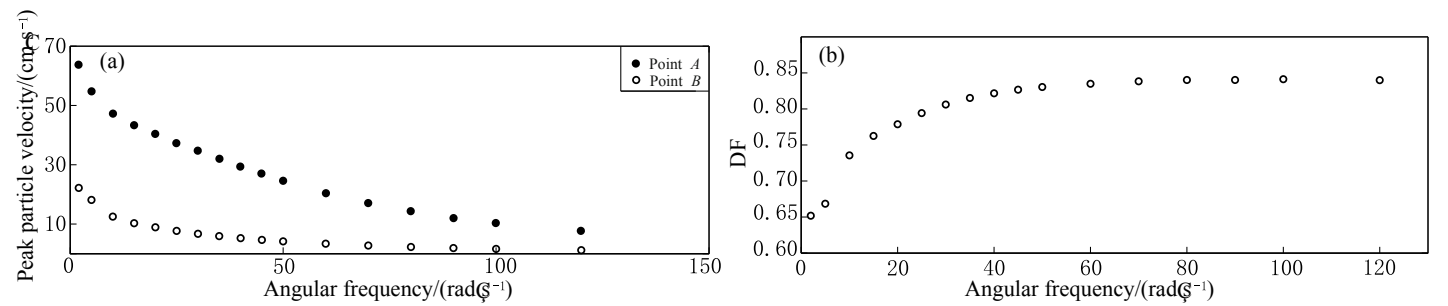

Figure 8 (a) Variation of maximum particle velocities at points $A$ and $B$ versus angular frequency. (b) The value of decay factor (DF) versus angular frequency.

Effect of load frequency on the dynamic damping of the developed model can be evaluated by definition of a non-dimensional parameter, namely decay factor (DF), which is defined as (Wang et al., 2010)

$$
\mathrm{DF}=\frac{V_{A}-V_{B}}{V_{A}}
$$

where $V_{A}$ and $V_{B}$ represent peak particle velocity at points $A$ and $B$, respectively. It should be noted that Wang et al. (2010) used peak axial stress instead of peak particle velocity; but, they are proportional to each other, equation (4) was employed as a DF.

Figure $8 \mathrm{~b}$ depicts the value of DF versus angular frequency. As shown in this figure, the value of DF increases with the angular frequency increasing. This finding infers that wave attenuation increases with any increase in the input load frequency. However, the rate of increment decreases with increase of load frequency.

In addition to the incident load frequency, natural frequencies of structures have influence on the structure response (Ghazvinian et al., 2010). In this section, effect of natural frequency of geotechnical models on the wave attenuation and dynamic damping of models are considered. Table 4 presents geomechanical properties of five models with different natural frequencies. Natural frequencies of models are determined by applying the gravity force to the numerical model with zero damping. Upon applying the gravity force, the model begins to oscillate and the natural frequency of oscillation with recording history of vertical displacement in the special time interval is determinable. The frequency of oscillation is used as a natural frequency of model.

Table 4 Geomechanical properties of five models with different natural frequencies

\begin{tabular}{ccccccc}
\hline $\begin{array}{c}\text { Bulk modulus } \\
\text { GPa }\end{array}$ & $\begin{array}{c}\text { Shear modulus } \\
/ \mathrm{GPa}\end{array}$ & $\begin{array}{c}\text { Cohesion } \\
/ \mathrm{MPa}\end{array}$ & $\begin{array}{c}\text { Friction } \\
\text { angle }{ }^{\circ}\end{array}$ & $\begin{array}{c}\text { Tensile strength } \\
/ \mathrm{MPa}\end{array}$ & $\begin{array}{c}\text { Density } \\
/\left(\mathrm{kg} \cdot \mathrm{m}^{-3}\right)\end{array}$ & $\begin{array}{c}\text { Natural frequency } \\
/ \mathrm{Hz}\end{array}$ \\
\hline 17.57 & 13.18 & 4.12 & 36 & 1.04 & 2600 & 13.00 \\
5.56 & 4.17 & 1.12 & 35 & 0.20 & 2600 & 7.20 \\
1.76 & 1.32 & 0.34 & 34 & 0.05 & 2600 & 4.00 \\
0.56 & 0.42 & 0.01 & 32 & 0.01 & 2600 & 2.50 \\
0.35 & 0.20 & 0.03 & 25 & 0.003 & 2600 & 1.60 \\
\hline
\end{tabular}

The developed numerical model (Figure 7) is used to evaluate the effect of natural frequency on the wave attenuation. For this purpose, five numerical models are performed based on the presented data in Table 4. A sinusoidal stress load with frequency of $4 \mathrm{~Hz}$ and amplitude of $1.0 \mathrm{MPa}$ is applied to the model, and the value of DF in the different geotechnical models, with different natural frequencies, are recorded. Figure 9 depicts the variation of DF with frequency ratio $(\eta)$, the ratio of incident load frequency to natural frequency of model.

Figure 9 shows that the minimum value of DF obtains when frequency ratio $\eta=1$. In other words, when the value of incident load frequency is equal to the natural frequency of model, minimum wave attenuation occurs.

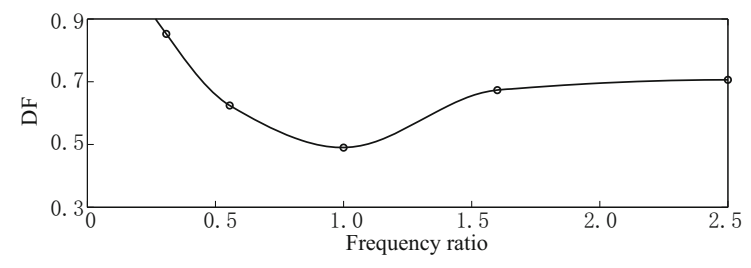

Figure 9 Variation of DF versus frequency ratio. 


\section{Conclusion}

This study deals with some fundamental considerations regarding ground motion parameters and behavior of underground structures under seismic loading. Analyses revealed that Arias intensity and specific energy of time histories with identical PGA are related to the frequency content of the seismic load.

Although $a_{\mathrm{rms}}$ is a more realistic measure than PGA for evaluation of earthquake intensity, there is no significant relationship between $a_{\mathrm{rms}}$ and PGV/PGA. This is because time durations of considered time histories are different. However, there is a reasonable relationship between $a_{\mathrm{rms}} \times T_{\mathrm{d}}$ and the ratio of $\mathrm{PGV} / \mathrm{PGA}$.

An increment in the ratio of $\mathrm{PGV} / \mathrm{PGA}$ increases the value of lining deflection and there is an exponential relationship between lining deflection and ratio of PGV/PGA.

Dynamic analysis of an underground structure using two separate time histories (Avaj and Chi-Chi earthquakes) with identical PGA and different frequency contents, presents different responses. Avaj seismic load, with smaller value of PGV/PGA ratio, causes less destructive effect on the underground structure than ChiChi seismic load.

With increasing frequency of incident dynamic loading to a geotechnical model, peak particle velocity of model decreases.

Loads with higher frequency attenuate faster than loads with lower one. The value of DF increases with the angular frequencies increasing. In other terms, wave attenuation increases with any increase in the incident load frequency. However, the rate of increment decreases with increasing of the load frequency.

When a geotechnical model was excited by a dynamic load possessing a frequency equal to natural frequency of the model, minimum wave attenuation occurs in the model.

\section{References}

Alvanitopoulos P F, Andreadis I and Elenas A (2010). Interdependence between damage indices and ground motion parameters based on Hilbert-Huang transform. Measurement Science and Technology 21(2): 025101, doi:10.1088/0957-0233/21/2/025101.

Arias A (1970). A measure of earthquake intensity. In: Hansen R J ed. Seismic Design for Nuclear Power Plants. Massachusetts Institute of Technology Press, Cambridge, MA, 438-483.

Baruah S, Baruah S, Kalita A and Kayal J R (2011). Ground motion parameters in Shillong and Mikir Plateau supple- mented by mapping of amplification factors in Guwahati City, Northeastern India. Journal of Asian Earth Sciences 42(6): 1 424-1 436.

BHRC (Building and Housing Research Center) (2008). Changureh-Avaj earthquake June 22th 2002. [2009-02-20]. http://www.bhrc.ac.ir/portal/Default.aspx?tabid=920.

Burdine N T (1963). Rock failure under dynamic loading conditions. Soc Pet Eng J 3(1): 1-8.

Chang J S (1989). Effect of damping on the dynamic response of soil systems. In: Proc 4th International Conference on Soil Dynamics and Earthquake Engineering. Mexico City, October 1989, 371-384.

Chen F, Ma C D and Xu J C (2005). Dynamic response and failure behavior of rock under static-dynamic loading. Journal CSUT 12(3): 354-358.

Clough R W and Penzien J (1994). Dynamics of Structures. 2nd Edition. McGraw Hill, New York, 738pp.

Douglas J (2003). Earthquake ground motion estimation using strong-motion records: a review of equations for the estimation of peak ground acceleration and response spectral ordinates. Earth-Science Reviews 61(1-2): 43104.

Ghazvinian A, Nejati H R and Hadei M R (2010). Effect of seismic load frequency on the behavior of underground structures. In: 6th Asian Rock Mechanics Symposium. New Delhi, India, 23-27 October, 2010, Paper No. 89.

Haimson B C and Kim C M (1972). Mechanical behaviour of rock under cyclic loading. In: 13th Symp. Rock Mech. University of Illinois, Urbana, Illinois, August 30 to September 1, 1971, 845-863.

Hashash Y M A, Hook J J, Schmidt B and Yao J I (2001). Seismic design and analysis of underground structures. Tunnelling and Underground Space Technology 16: 247293.

Jafari M K, Pellet F, Boulon M and K Amini Hosseini (2004). Experimental study of mechanical behaviour of rock joints under cyclic loading. Rock Mechanics and Rock Engineering 37: 3-23.

Kappos A J (2002). Dynamic Loading and Design of Structures. Spon Press, London, 374pp.

Kavazanjian Jr E, Echezuria H and McCann M W (1985). RMS acceleration hazard for San Francisco. Soil Dynamics and Earthquake Engineering 4(3): 106-123.

Lajtai E Z, Duncan E J and Carter B J (1991). The effect of strain rate on rock strength. Rock Mech Rock Eng 24: 99-109.

Nejati H R (2009). Dynamic Analysis of Railway Tunnels. [MS Dissertation]. Tarbiat Modares University, Tehran, Iran, 117pp (in Persian).

PEER (Pacific Earthquake Engineering Research Center) Database (2005). PEER ground motion database. [200902-20]. http://peer.berkeley.edu.

Penzien J (2000). Seismically-induced racking of tunnel linings. Int J Earthquake Eng Struct Dyn 29: 683-691. 
Power M S, Rosidi D and Kaneshiro J (1996). Vol. III Strawman: Screening, Evaluation, and Retrofit Design of Tunnels. Report Draft. National Center for Earthquake Engineering Research, Buffalo, New York.

Ray S K, Sarkar M and Singh T N (1999). Effect of cyclic loading and strain rate on the mechanical behaviour of sand stone. Int J Rock Mech Min Sci 36: 543-549.

Sano O, Ito I and Terada M (1981). Influence of strain rate on dilatancy and strength of Oshima granite under uniaxial compression. J Geophys Res 86: 9 299-9 311.

Seismosoft (2011). SeismoSignal — v4.3.0 software. [2011-0622]. http://www.seismosoft.com.

Strasser F O and Bommer J J (2009). Large-amplitude ground-motion recordings and their interpretations. Soil Dynamics and Earthquake Engineering 29(10): 1 305-
1329 .

Wang J N (1993). Seismic Design of Tunnels: A State-of-theArt Approach. Parsons Brinckerhoff Quade \& Douglas, Inc., New York, 159.

Wang W H, Li X B, Zhang Y P and Zuo Y J (2007). Closure behavior of rock joint under dynamic loading. Journal of Central South University of Technology 14(3): 408-412.

Wang W L, Wang T T, Su J J, Lin C H, Seng C R and Huang T H (2001). Assessment of damage in mountain tunnels due to the Taiwan Chi-Chi earthquake. Tunneling and Underground Space Technology 16(13): 133-150.

Wang Z L, Konietzky H and Shen R F (2010). Analytical and numerical study of P-wave attenuation in rock shelter layer. Soil Dynamics and Earthquake Engineering 30: $1-7$. 